\title{
Autism Associated with Tetrasomy 15: A Further Report
}

\author{
Mohammad Ghaziuddin, Susan Sheldon, Sanjiv Venkataraman, Luke Tsai and Neera \\ Ghaziuddin*
}

\begin{abstract}
Association of autism with tetrasomy of chromosome 15 has recently been described in six males. In this report, we describe the occurrence of autism in a girl with tetrasomy of chromosome 15 . The patient showed hyperactivity, hand-flapping, short-stature, eye abnormalities, and hypotonia, which have been reported in males with tetrasomy of chromosome 15 . This suggests that autism may be associated in both sexes with a distinct syndrome characterized by tetrasomy of chromosome 15 , mental retardation and characteristic physical features.
\end{abstract}

\section{Introduction}

Autism is a behavioural syndrome characterized by abnormalities in reciprocal social interactions, patterns of communication, and restricted interests and activities (WHO, 1992). A variety of aetiological factors ranging from infectious agents to metabolic abnormalities have been proposed as being associated with this disorder. Chromosomal abnormalities have also been described as further evidence of the organic nature of the syndrome. Most of these abnormalities described to date have involved sex chromosomes (Reiss et al., 1986); structural autosomal defects have been rarely reported. Thus, Hansen et al. (1977) described a 14year-old severely mentally retarded autistic girl who presented with hyperactivity, aggression, and epilepsy. She had an extra bisatellited chromosome, which was a translocation between chromosome 22 and a chromosome belonging to the $\mathrm{D}$ group, most probably number 13 , with a karyotype of $47, X X,+t(22 ; 13)$ (pter-q13). Wakabayashi (1979) described the association of Down syndrome (trisomy 21) with autism; and Turner and Jennings (1961) reported on chromosome 22 abnormalities in this disorder. Mariner et al. (1986) described four mentally retarded autistic patients with structural autosomal abnormalities, including inversion/duplication of $3 p$ and $16 q$, and $5 p+$ and $17 p-$; while Saliba and Griffiths (1990) described the occurrence of an autosomal fragile site, fra (2) (q13), in a 12 year-old patient with Asperger syndrome, widely regarded as a mild variant of autism.

More recently, Gillberg et al. (1991) described the association of partial trisomy of chromosome 15 with autism. They described six males, ranging in age from 4 to 32 years, who were moderately to severely mentally retarded. The patients presented with a combination of hyperactivity, extreme thinness, short-stature, high-arched palate, eye abnormalities (epicanthic folds and hypertelorism), hypotonia and epilepsy. On the basis of chromosomal analysis, they suggested that the patients were tetrasomic for the short arm and part of the long arm close to the centromere of chromosome 15 (photographs of the karyotype were

Table 1. Summary of clinical features in Marker Chromosome.

\begin{tabular}{lc}
\hline $\begin{array}{l}\text { Clinical features described } \\
\text { in the literature }\end{array}$ & $\begin{array}{c}\text { Present in } \\
\text { Patient } M\end{array}$ \\
\hline Hyperactivity & Yes \\
Episodic hyperventilation & No \\
Mental retardation (severe to profound) & Yes \\
Small and thin & Yes \\
Kyphosis (scoliosis) & Yes \\
Epicanthic folds & Yes \\
Hypertelorism & No \\
High-arched palate & No \\
Big protruding ears & No \\
Hypotonus & Yes \\
Epilepsy & Yes \\
\hline
\end{tabular}

* Division of Child Psychiatry, Psych Annex, 200 E. Hospital Drive, University of Michigan Medical Center, Ann Arbor, MI, USA, 48109-0290 
not provided). Since the marker chromosome appeared to be a supernumerary part of chromosome 15 , they labelled this as partial trisomy 15 . However, as the total number of copies of genes present is four, use of the term tetrasomy would be more appropriate. Clinical features of this association are summarized in Table 1.

In this report, we present the first case of autism in a female with tetrasomy of chromosome 15 . We propose that there may exist a subgroup of autistic persons with tetrasomy of chromosome 15 who present with distinct clinical features.

\section{Case history}

$M$, a five-year-old Caucasian girl, was referred for an evaluation of her long-standing problems in social interaction and communication. Full details of the developmental history during the first two years of her life were not available. This was because her biological mother died in a car accident when $M$ was about three years old, and her father, who was then in the armed forces, was posted out of town during her early development. However, according to the records, M's biological mother suffered from vaginal bleeding in the first four mionths of pregnancy, although rest of the pregnancy and the labour were normal.

$M$ had trouble feeding and was described as a floppy baby. She developed seizures at the age of about five months which lasted till she was 18 months old and were treated with valproate. She was noted to be slow in holding her head and in sitting without support. When she was about two years of age, she was referred for suspected developmental delay. A diagnosis of cerebral palsy was made. In addition, presence of Moebius syndrome was also considered because of bilateral abducent nerve palsy, hypotonia, and esotropia. However, there was no general agreement about this diagnosis because other features of the syndrome, such as congenital abnormalities of extremities, absence of pectoral muscles and bulbar involvement, were not present (Baraitser, 1977). She was operated upon for bilateral strabismus at about four years of age.

At the time of the present referral at the age of five years, adoptive mother reported persisting problems in communication and social interaction compared to other children of her age. $M$ did not mix with other children and when placed in a group of children her age, preferred to play by herself. Her vocabulary was limited. She repeated words and sentences over and over, usually out of social context. In addition, she showed a number of abnormal movements including flapping of her hands and thythmic patterns of patting herself.

On examination, $M$ appeared shorter than her age. Her face was mildly dysmorphic with the left side being smaller than the right and the left angle of the mouth and the left palpebral fissure forming an acute angle. She had a flat occiput and the left side of her face also receded towards her occiput. There was no prognathism. She had simple ears with a decreased prominence of her antihelix. Her nose was small and antiverted. She had bilateral epicanthal folds, and both her ears were normally positioned. Her palate was normal. There was mild bilateral fifth digit clinodactyly. Her back showed mild scoliosis; her chest and abdomen were unremarkable. A detailed neurological examination was not possible; however, there were no abnormalities of deep tendon reflexes and her toes were downgoing. Soft neurological signs such as difficulty in standing or hopping on one foot were noted. During the interview, she hardly looked at the examiners. She wandered aimlessly round the room, making little attempt to play with the toys offered. She seemed to be fascinated by a table-clock, constantly winding and unwinding it. She kept repeating the conversation between the examiners and her mother, despite being asked not to do so. In addition, she exhibited flapping of her hands and occasional hopping.

Other investigations revealed the following: on the Stanford-Binet test (Thorndike et al., 1986), her test composite score was 49 . Speech and language assessment revealed significant receptive, expressive and pragmatic deficits. On the Childhood Autism Rating Scale (CARS, Schopler et al., 1985), she showed significant abnormalities in the following areas: relationship with people, verbal and motoric imitation; visual responsiveness, and verbal communication. Her score of 37 (with four items scored three or higher) on the CARS placed her in the mild to moderately autistic range. On the Vineland Adaptive Behaviour Scales (Sparrow et al., 1984), significant deficits were found in areas of social interaction; communication; play; and motor skills, with a standard score of 41 . In the area of motor skills, she was found to have problems with both gross and fine motor coordination. She had not developed bilateral motor coordination and continued to walk downstairs without al- 


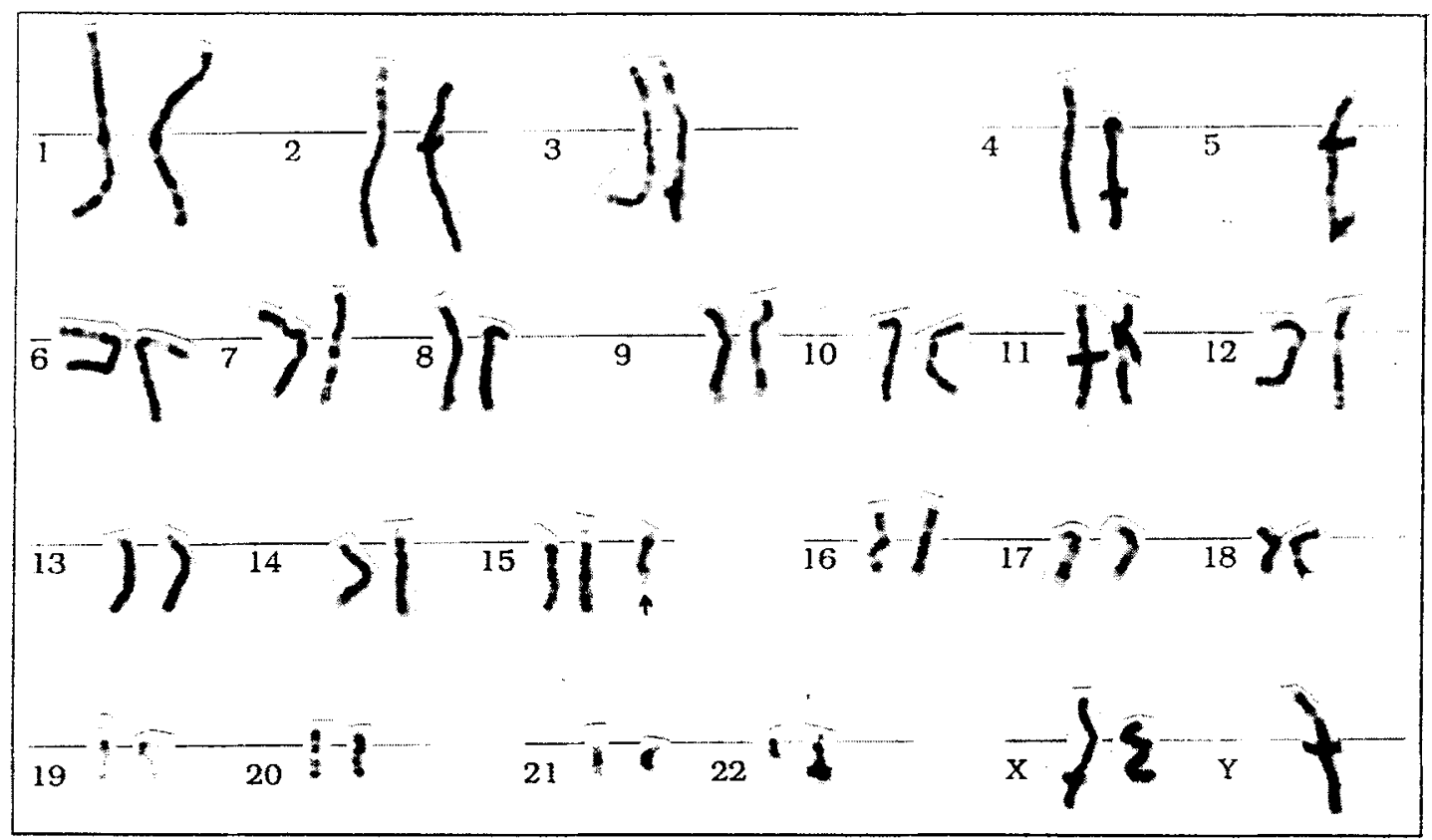

Figure 1. Picture of the marker chromosome 15.

ternating her feet. She was unable to pedal a tricycle or hop on one foot. Her running ability was also awkward. She had difficulty in putting simple puzzles together and manipulating objects such as pencils and scissors. An Autism Behaviour Checklist (Krug et al., 1980), was also administered; this showed a marked correlation of scores given by father, adoptive mother and her teacher. All scores were in the autistic range (105 to 111). A CT scan of the head and an EEG were normal. Based on these findings, a diagnosis of DSMIII-R autistic disorder (APA, 1987) was made. According to the symptom checklist for autistic disorder, she met the following criteria: a qualitative impairment in her ability to engage in reciprocal interaction; difficulty in making peer relationships; lack of imitation and imaginative social play; marked. abnormal nonverbal conversation as shown by lack of eye contact; inability to start and sustain conversation; impairment in both form and content of speech as suggested by echolalia, monotonous tone and perseveration; and the presence of stereotyped body movements. In addition, based on her IQ and overall functioning, an additional diagnosis of mental retardation was also given.

\section{Chromosomal Analysis}

Routine peripheral blood lymphocyte cultures were established for cytogenetic analysis. Cytogenetic evaluation of Giemsa banded metaphases revealed a bisatellited marker chromosome (47, $\mathrm{XX},+$ marker). Staining of metaphases with distamycin A-DAPI (4'6-diamidino-2-phenyllindole) proved the marker to be derived from chromosome 15 (Schweizer et al., 1978); thus her karyotype was $47, \mathrm{XX}$, +inv dup (15) (p13q12). The patient was therefore termed as being functionally tetrasomic for the short arm and the proximal long arm of chromosome 15. A picture of the marker chromosome is shown above (Figure 1).

\section{Discussion}

This patient bears a marked resemblance to the group of six autistic males with tetrasomy 15 described by Gillberg et al. (1991) with the exception that she was female. There were marked similarities between her clinical features and those described by Gillberg et al. (1991): hyperactivity, 
hand-flapping, severe mental retardation, short stature, eye abnormalites, problems with coordination, hypotonia, and a history of epilepsy. As in the patient reported here, Gillberg's patients were also tetrasomic for the short arm and part of the long arm of chromosome 15 . Other reports of similar abnormalities of chromosome 15 have described the presence of mental retardation but autism has not been reported (Buckton et al., 1985; Maraschio et al., 1981). Although no causative links can be proposed on the basis of a few reports, the present case lends support to the possible existence of a distinct subtype associated with tetrasomy of chromosome 15 in autism, as proposed by Gillberg and colleagues (1991).

Despite the known association between autism and chromosome abnormalities, it is not clear if the relationship is one of cause and effect. With the possible exception of fragile $\mathrm{X}$ syndrome (Brown et. al., 1986), no other chromosome abnormality has been proposed as having a special association with autism. While the possible existence of a subgroup in autism involving abnormalities of chromosome 15 is appealing, it is also likely that, like the previous reports of chromosomal defects in autism, this report may also represent coincidental findings.

\section{Résumé}

L'association d'autisme avec une tétrasomie du chromosome 15 a été décrite récemment chez six garçons. Dans cet article, nous décrivons la survenue d'un autisme chez une fille avec une tétrasomie du chromosome 15. La patiente présentait une hyperactivité, un battement des mains, une petite taille, des anormalités des yeux et une hypotonie qui ont été rapportées chez des garçons avec tétrasomie du chromosome 15 . Ceci suggère que l'autisme peut être associé dans les deux sexes avec un syndrome distinct caractérisé par une tétrasomie du chromosome 15 , un retard mental et des traits physiques caractéristiques.

\section{Zusammenfassung}

Kürzlich wurde eine Assoziation einer Tetrasomie des Chromosoms 15 mit Autismus bei 6 männlichen Individuen beschrieben. In dem vorliegenden Fallbericht wird das Vorkommen eines Autismus bei einem Mädchen mit einer Tetrasomie des Chromosoms 15 dargestellt. Die Patientin zeigte Hyperaktivität, Handstereotypien, ophthalmologische Auffälligkeiten und Hypotonie. Diese Auffälligkeiten sind auch bei den männlichen Individuen mit einer Tetrasomie 15 beschrieben worden. Diese Befunde legen nahe, daß bei beiden Geschlechtern Autismus mit einem eigenständigen Syndrom im Falle des Vorliegens einer Tetrasomie 15 einhergeht, dessen wesentliche Merkmale geistige Behinderung und charakteristische Auffälligkeiten sind.

\section{References}

American Psychiatric Association (1987). Diagnostic and Statistical Manual of Mental Disorders, Third edition, Revised. Washington, DC: APA.

Baraitser, M. (1977). Genetics of Moebius Syndrome. Joumal of Medical Genetics, 14, 415-417.

Brown, W.T., Jenkins, E.C., Cohen, I.L., Fisch, G.S., Wolf-Schein, E.G., Gross, A., Waterhouse, L., Fein, D., Mason-Brothers, A., Ritvo, E., Ruttenburg, B.A., Bently, W. \& Castells, S. (1986). Fragile-X and autism: A multicenter survey. American Journal of Medical Genetics, 23, 341-352.

Buckton, K.E., Spowart, G., Newton, M.S. \& Evans, H.J. (1985). Forty-four probands with an additional "marker" chromsome. Human Genetics, 69, 353-370.

Gillberg, C., Steffenburg, S., Wahlstrom, J., Gillberg, I.C., Sjostedt, A., Martinsson, T., Liedgren, S. \& Eeg-Olofsson, O. (1991). Autism associated with marker chromosome. Journal of the Amercian Academy of Child and Adolescent Psychiatry, 30, 489-494.

Hansen, A., Brask, B.H., Nielsen, J., Rasmussen, K. \& Sillesen, I. (1977). A case report of an autistic girl with an extra bisatellited marker chromosome. Joumal of Autism and Childhood Schizophrenia, 7, 263-267.

Krug, D.A., Arick, J. \& Almond, P. (1980). Behavior checklist for identifying severely handicapped individuals with high levels of autistic behavior. Joumal of Child Psychology and Psychiatry, 21, 221-229.

Maraschio, P., Zuffardi, O., Bernardi, F., Bozzola, M., De Paoli, C., Fonatsch, C., Flatz, S.D., Ghersini, L., Gimelli, G., Loi, M., Lorini, R., Peretti, D., Poloni, L., Tonetti, D., Vanni, R. \& Zamboni, G. (1981). Preferential maternal derivation in inv dup (15): analysis of eight new cases. Human Genetics, 57, 345350.

Mariner, R., Jackson, A.W., Levitas, A., Hagerman, R.J., Braden, M., McBogg., P.M., Smith, A.C.M. \& Berry, R (1986). Autism, mental retardation and chromosomal abnormalities. Journal of Autism and Developmental Disorders, 16, 425-440. 
Reiss, A.L., Feinstein, C. \& Rosenbaum, K.N. (1986). Autism and Genetic Disorders. Schizophrenia Bulletin, $12,724-738$.

Saliba, J.R. \& Griffiths, M. (1990). Autism of the Asperger type associated with an autosomal fragile site. Joumal of Autism and Developmental Disorders, 20, 569-575.

Schweizer, D., Ambrose, P. \& Anderle, M. (1978). Modification of DAPI banding on human chromosomes by prestaining with a DNA-binding oligopeptide antibiotic, Distamycin A. Experimental Cellular Research, 111, 327-332.

Schopler, E., Reichler, R.J. \& Renner, B.R. (1985). Childhood Autism Rating Scale (CARS). New York: Irving Publishers.
Sparrow, S.S., Balla, D.A. \& Cicchetti, D.V. (1984). Vineland Adaptive Behavior Scales. Circle Pines, MI American Guidance Service.

Thorndike, R.L., Hagen, E.P. \& Satler, J.M. (1986). The Stanford-Binet Intelligence Scale: Fourth edition Chicago: The Riverside Publishing. Company.

Turner, B. \& Jennings, A.N. (1961). Trisomy for chromosome 22. Lancet, I, 49-50.

Wakabayashi, S. (1979). A case of infantile autism associated with Down syndrome. Joumal of Autism and Developmental Disorders, 9, 1-36.

World Health Organization (1992). The ICD-10 classification of mental and behavioural disorders. Geneva: WHO.

\section{Corrigendum}

Gillberg, I.C., Winnergård, I. \& Gillberg, C. (1993). Screening methods, epidemiology and evaluation of intervention in DAMP in preschool children. European Child and Adolescent Psychiatry, 2 (3), 121-135.

On page 134 of the above-mentioned paper, the following paragraph was inadvertently left out under the Appendix:

The following 6 questions from the Preschool Questionnaire were used in the screening study and formed the basis for deciding on the criterion level for abnormality: $5,14,22,24,26$, and 32 . This set of 6 questions was derived after stepwise discriminant analysis of the 34 items on the questionnaire which had been applied to community-based samples of 6-year-old children with and without DAMP (Gillberg, C. \& Rasmussen, P. (1982). Perceptual, motor and attentional deficits in six-year-old children. Screening procedure in preschool. Acta Paediatrica Scandinavica, 71, 121-129). 